\title{
Soluble Expression and Purification of Human Tissue-type Plasminogen Activator Protease Domain
}

\author{
Hak Joo Lee and Hana Im* \\ Department of Molecular Biology, Sejong University, Seoul 143-747, Korea. ${ }^{*}$ E-mail: hanaim@sejong.ac.kr \\ Received March 17, 2010, Accepted July 27, 2010

\begin{abstract}
Human tissue-type plasminogen activator (tPA) is a valuable thrombolytic agent used to successfully treat acute myocardial infarction, thromboembolic stroke, peripheral arterial occlusion, and venous thromboembolism. Recombinant tPA is accumulated as an inactive form in inclusion bodies of $E$. coli and is refolded in vitro, which is accompanied by extensive aggregation. In the present study, a tPA protease domain was expressed in an active soluble form in the cytosol of E. coli Rosetta-gami cells, which allowed disulfide bond formation and supplied the tRNA molecules required for six rarely used codons in E. coli. This strategy increased the amount of soluble protease domain protein and avoided the cumbersome refolding process. The purified protease domain not only degraded tPA substrate peptides but also formed a covalently bound complex with plasminogen activator inhibitor-1, as does full-length tPA. Soluble expression and purification of tPA domains may aid in functional analyses of this multi-domain protein, which has been implicated in many physiological and pathological processes.
\end{abstract}

Key Words: Tissue-type plasminogen activator, Disulfide bond, Plasminogen activator inhibitor-1, Rare codon, Protein expression

\section{Introduction}

Human tissue-type plasminogen activator (tPA) is a serine protease that cleaves plasminogen, an inactive proenzyme, to form plasmin, the active enzyme. Plasmin degrades fibrin into soluble fragments. ${ }^{1}$ The thrombolytic effect of tPA has been applied clinically to treat thrombosis, which can cause heart attack and stroke. ${ }^{2}$ Originally, human tPA was purified from human uterus. ${ }^{3}$ The availability of the cDNA for human tPA allowed recombinant $\mathrm{tPA}$ production by Chinese hamster ovary cells in large-scale tissue culture. ${ }^{4}$ In addition to its high cost, this mammalian expression method produced a glycosylated form of tPA, which is more rapidly removed from circulation. ${ }^{5}$

The initial attempts at expressing tPA in Escherichia coli have yielded small amounts of tPA in inclusion bodies. There are two major obstacles to the production of tPA in E. coli: disulfide bond formation and rare codon usage. The whole tPA molecule contains 17 disulfide bonds and a free Cys at position $83 .{ }^{6}$ However, the formation of stable disulfide bonds in the E. coli cytoplasm is strongly disfavored, owing to its high concentrations of reduced glutathione and thioredoxins. ${ }^{7}$ Thus, tPA cannot fold properly in the E. coli cytoplasm and can accumulate in inclusion bodies. Protein oxidation in the periplasm may be detrimental for the folding of proteins with several disulfide bonds, because of the randomness of disulfide bond formation by DsbA, a disulfide bridge-forming enzyme. ${ }^{8}$ It has been reported that deletions of thioredoxin reductase $(\operatorname{tr} x B)$ and glutathione oxidoreductase ( $g o r$ ) raise the redox potential of the cytoplasm, thereby favoring disulfide bond formation in certain proteins such as alkaline phosphatase. ${ }^{9}$

Codon usage varies among organisms and may lead to inefficient translation of mammalian genes in bacterial hosts. ${ }^{10}$ The codons AGG, AGA, CUA, AUA, GGA, and CCC are rare in E. coli. ${ }^{11}$ However, the tPA coding sequence requires a signifi- cant portion of these rare codons, especially AGA and AGG, which appear at a frequency of $3.24 \%$. Augmentation with $\arg U$ (decoding AGA/AGG) and $\arg W$ (decoding AGG) genes improved tPA production in E. coli. ${ }^{12}$ Nevertheless, tPA was still produced as an inactive enzyme in inclusion bodies and required complicated renaturation steps, resulting in high costs and low yields.

Human TPA is a polypeptide composed of 527 residues and contains five domains ${ }^{1}$ : the N-terminal F-domain, which contains 47 residues (residues 4-50) and is homologous to the finger domain; the E-domain (residues 50-87), which is homologous to epidermal growth factor; two kringle domains (K1domain, residues 87-175; K2-domain, residues 176-256), which share a high degree of homology with the five kringle domains of plasminogen; and the P-domain (residues 276-527), which encodes a serine protease with an archetypal catalytic triad of Ser 478, His 322, and Asp 371. ${ }^{13}$ The F- and K2-domains are reportedly responsible for binding fibrin. ${ }^{5}$ Native tPA, initially synthesized as a single-chain molecule, can be cleaved by plasmin at the Arg275-Ile276 peptide bond and thus converted to a two-chain tPA molecule held together by one interchain disulfide bond. ${ }^{14}$

In addition to fibrinolysis, recent studies have uncovered other physiological roles for tPA, including the promotion of long-term potentiation, ${ }^{15}$ neuroprotection against ischemia and seizures, ${ }^{16}$ and microglial activation. ${ }^{17}$ These functions are independent of the protease activity of tPA, ${ }^{18}$ and the domains responsible for these activities have yet to be elucidated.

To facilitate the functional analysis of each domain and to make the molecular properties of tPA more amenable to practical applications, it is necessary to engineer an efficient process for the production of recombinant tPA. Toward this end, the current study evaluates several $E$. coli strains and culture conditions for efficient expression of the tPAP-domain in a soluble, 
functional form. In particular, the effects of supplying rare codon tRNAs and modulating the redox potential in the cytoplasm were evaluated.

\section{Experimental}

Cloning of tPA P-domain. A cDNA encoding human tPA was purchased from American Type Culture Collection (ATCC number 40403). The fragment coding for P-domain was obtained using PCR amplification. The forward primer sequence was 5'-CCTCCATGGCCACCTGCGGCCTGAGACAG-3' and the backward primer was 5'-TGTAAGCTTGAATCCAGTCTA GGTAGTTGTTAAC-3'. The PCR mixture consisted of $5 \mu \mathrm{L}$ of $10 \times$ PCR buffer (final concentrations: $10 \mathrm{mM} \mathrm{KCl}, 0.01 \%$ gelatin, $20 \mathrm{mM}$ Tris-HCl, pH 9.0), $2.5 \mathrm{mM} \mathrm{MgCl}_{2}, 0.2 \mathrm{mM}$ for each dNTP, $200 \mathrm{nM}$ for each primer, $0.5 \mu \mathrm{L}$ of template DNA, and 2.5 units of $P f u$ DNA polymerase (Promega Co., USA) in the final $50 \mu \mathrm{L}$ volume. The PCR was performed in a DNAEngine thermal cycler (Bio-Rad Laboratories Inc., USA) using a cycling condition that consisted of an initial denaturation at $95^{\circ} \mathrm{C}$ for 5 min and then 30 cycles with denaturation at $94{ }^{\circ} \mathrm{C}$ for 30 seconds, annealing at $56^{\circ} \mathrm{C}$ for 30 seconds, and extension at $72{ }^{\circ} \mathrm{C}$ for $2 \mathrm{~min}$. A final extension was performed at $72{ }^{\circ} \mathrm{C}$ for $5 \mathrm{~min}$. Two blanks that contained all the components of the reaction mixture except each of the two primers were used as controls.

The PCR products were double-digested with $\mathrm{NcoI}$ and HindIII restriction endonucleases, and DNA fragments that were $0.8 \mathrm{~kb}$ in size were then cloned on a pRSET B vector (Invitrogen Co., USA) digested with the same enzymes. The cloned DNA was verified by sequencing analysis, and the resulting plasmid for tPA P-domain-expression in E. coli was named pRSET-tPAP.

Expression of tPA P-domain in E. coli. Several E. coli strains were transformed with the recombinant pRSET-tPAP plasmid. Transformed cells were selected on Luria-Bertani (LB) medium plates supplemented with $100 \mu \mathrm{g} / \mathrm{mL}$ ampicillin and, if necessary, $30 \mu \mathrm{g} / \mathrm{mL}$ chloramphenicol (USB Co., NJ, USA). For overproduction of tPA P-domain, $1 \mathrm{~mL}$ of the overnight liquid culture was transferred to a flask containing $50 \mathrm{~mL}$ fresh LB medium that contained the same antibiotics. Cells were grown with vigorous shaking to a density of $\mathrm{OD}_{600} \approx 0.4$, and overproduction of recombinant protein was induced with the addition of IPTG to the final concentration of $0.1 \mathrm{mM}$. The cultures were incubated further at $30{ }^{\circ} \mathrm{C}$ or $37{ }^{\circ} \mathrm{C}$ for various times with vigorous shaking. Overexpression of the tPAP-domain protein was analyzed by $10 \%$ SDS-polyacrylamide gel electrophoresis and Western blotting analysis using a rabbit His-probe (H-15) antibody (Santa Cruz sc-803).

Purification of soluble tPA P-domain protein. For tPA purification, E. coli Rosetta-gami cells transformed with pRSETtPAP was inoculated in LB medium that contained selective antibiotics. Five $\mathrm{mL}$ of the overnight liquid culture was transferred to each of four flasks containing $250 \mathrm{~mL}$ fresh LB medium, and tPA protein was induced by the addition of IPTG at $30^{\circ} \mathrm{C}$ for $4 \mathrm{~h}$. After harvest and lysis of cells by sonication using a Bandelin Sonoplus HD2200 ultrasonic homogenizer (Berlin, Germany) with a TT13 tip at 50\% cycle ( $1 \mathrm{~min} \times 3$ times $)$, the supernatant and pellet fractions from these cell lysates were separated by centrifugation in a centrifuge (Hanil Micro 17R+, Incheon, Korea) at $10,000 \mathrm{rpm}$ for $10 \mathrm{~min}$ at $4{ }^{\circ} \mathrm{C}$. The supernatant fraction containing soluble recombinant tPA proteins was loaded on a $\mathrm{Ni}^{2+}$-NTA chelating agarose CL-6B column (Peptron Co., Korea) in a buffer (20 mM Tris-Cl, $5 \mathrm{mM}$ imidazole, and $0.5 \mathrm{M} \mathrm{NaCl}, \mathrm{pH} 7.4$ ). The protein was eluted using an imidazole gradient from $5 \mathrm{mM}$ to $500 \mathrm{mM}$. Concentrations of proteins were determined using Bio-Rad DC (detergent compatible) protein assay kit.

Determination of the IPA activity. The tPA protease activity of P-domain protein was determined via a direct chromogenic assay using $50 \mu \mathrm{M}$ Spectrozyme tPA (methylsulfonyl-D-cyclohexyltyrosyl-Gly-Arg- $p$-nitroanilide; American Diagnostica Inc., USA). The tPA assay buffer was $30 \mathrm{mM}$ Tris, $30 \mathrm{mM}$ imidazole, $100 \mathrm{mM} \mathrm{NaCl}$, and $25 \mathrm{mM} \mathrm{HCl}, \mathrm{pH}$ 7.9. The proteins were incubated with the substrate at $37{ }^{\circ} \mathrm{C}$ for various times. The amount of products was measured by a spectrophotometer (Beckman DU650) at $410 \mathrm{~nm}$, and calculated using a molar absorption coefficient of $8,800 \mathrm{M}^{-1} \mathrm{~cm}^{-1}$ for $p$-nitroaniline. Single-chain recombinant tPA (American Diagnostica Inc., USA), secreted from a Chinese hamster ovary cell line transfected with the cDNA for human tPA, was used for comparison of protease activity.

To monitor covalently-bound complex formation with plasminogen activator inhibitor-1 (PAI-1), $4 \mu \mathrm{g}$ of PAI-1 protein was incubated with either $2 \mu \mathrm{g}$ of single-chain tPA or $1.5 \mu \mathrm{g}$ of purified tPAP-domain proteins in $30 \mu \mathrm{L}$ of tPA assay buffer for $10 \mathrm{~min}$ at $37{ }^{\circ} \mathrm{C}$. Appearance of the SDS-resistant tPA (or Pdomain)-PAI-1 complex was monitored by $10 \%$ SDS-polyacrylamide gel electrophoresis. The protein bands were visualized by staining with Coomassie Brilliant Blue.

\section{Results and Discussion}

Overexpression of tPA P-domain in a soluble form. The expression levels of tPA P-domain were examined in several strains of E. coli listed in Table 1. Different strains harboring the pRSET-tPAP plasmid were grown with vigorous shaking to a density of $\mathrm{OD}_{600} \approx 0.4$. Overproduction of recombinant protein was induced with the addition of IPTG and incubation at $37^{\circ} \mathrm{C}$ for $3 \mathrm{~h}$. Approximately $1.1 \times 10^{9}$ cells were harvested and lysed by sonication. The cell lysate was separated by highspeed centrifugation, and the expression levels of tPA P-domain in the supernatant and pellet fractions were determined by SDSpolyacrylamide gel electrophoresis and Western blot analysis. The tPA P-domain was expressed predominantly as an insoluble protein in inclusion bodies, and the level of expression was enhanced in $E$. coli strains [CodonPlus(DE3)-RIL, CodonPlus (DE3)-RP, and Rosetta-gami(DE3)pLysS] containing extra copies of the tRNA genes for the rarely used codons (Figure 1, top). The insoluble protein fractions were assayed for proteolytic activity toward Spectrozyme tPA, a chromogenic peptide substrate. Despite the large amounts of tPA P-domain protein in the inclusion bodies, negligible proteolytic degradation of the substrate over the background level was observed, as expected. This result suggests that the inclusion bodies contained inactive forms of P-domain protein, which may need to be 
Table 1. E. coli strains used in this study

\begin{tabular}{|c|c|}
\hline & Genotype \\
\hline BL21(DE3) & $\mathrm{F}^{-}$ompThsdS $S_{\mathrm{B}}\left(\mathrm{r}_{\mathrm{B}}^{-} \mathrm{m}_{\mathrm{B}}^{-}\right) \mathrm{gal} d c m(\mathrm{DE} 3)$ \\
\hline BL21(DE3)pLysS & $\mathrm{F}^{-}$ompT hsd $S_{\mathrm{B}}\left(\mathrm{r}_{\mathrm{B}}{ }^{-} \mathrm{m}_{\mathrm{B}}\right)$ gal dcm (DE3) pLysS $\left(\mathrm{Cam}^{\mathrm{R}}\right)$ \\
\hline Codon plus(DE3) RIL & 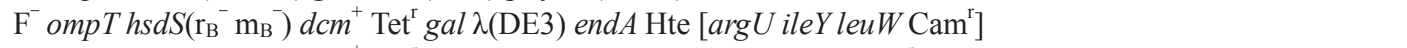 \\
\hline Codon plus(DE3) RP & 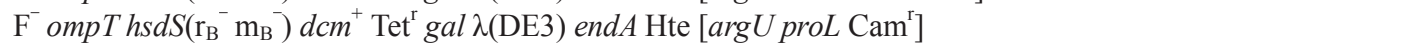 \\
\hline Rosetta-gami(DE3)pLysS & $\begin{array}{l}\Delta(\text { ara leu }) 7697 \Delta \text { lacX74 } \triangle \text { phoA PvulI phoR araD139 ahpC gale galK rpsL (DE3) } \mathrm{F}^{\prime}\left[\text { lac }^{+} \text {lacl }^{q} \text { pro }\right] \text { gor } 522:: \operatorname{Tn} 10 \\
\text { trxB pLysSRARE }{ }^{2}\left(\operatorname{Cam}^{\mathrm{R}}, \operatorname{Kan}^{\mathrm{R}}, \operatorname{Str}^{\mathrm{R}}, \operatorname{Tet}^{\mathrm{R}}\right)\end{array}$ \\
\hline
\end{tabular}

(a)

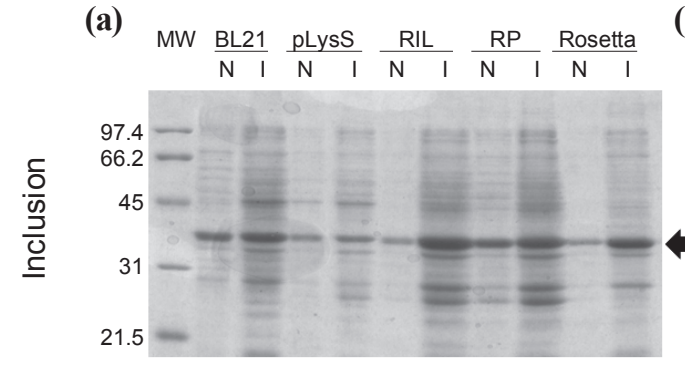

(c)

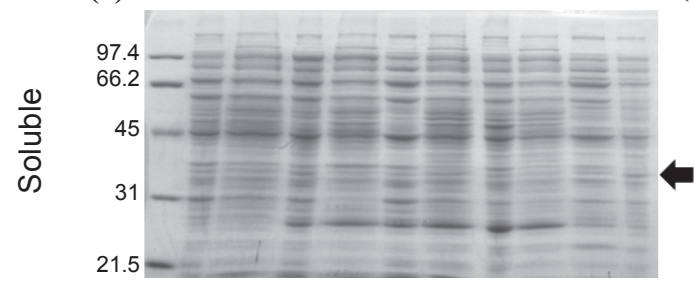

(b)

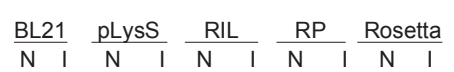

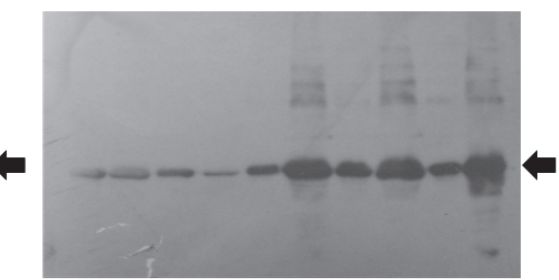

(d)

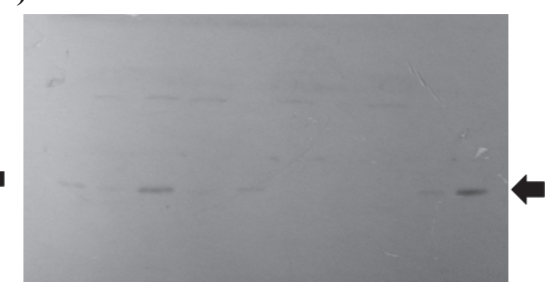

Figure 1. Expression of tPA P-domain in different $E$. coli strains. After induction of tPA P-domain expression with $0.1 \mathrm{mM}$ IPTG, cells were incubated at $37^{\circ} \mathrm{C}$ for $3 \mathrm{~h}$. The pellet (inclusion body) and supernatant (soluble) fractions of the whole cell lysate were subjected to electrophoresis on a $10 \%$ SDS-polyacrylamide gel and visualized by staining with Coomassie Brilliant Blue (a \& c), and by western blot analysis using antiHis-probe antibody (b \& d). Lane MW, molecular weight markers (Bio-Rad, low range); N, non-induced cells taken at the time of IPTG addition; I, induced cells taken at $3 \mathrm{hr}$ after IPTG addition; BL21, E. coli BL21(DE3) cells carrying pREST-tPAP; pLysS, E. coli BL21(DE3)pLysS cells carrying pREST-tPAP; RIL, E. coli Codon plus(DE3) RIL cells carrying pREST-tPAP; RP, E. coli Codon plus (DE3) RP cells carrying pRESTtPAP; Rosetta, E. coli Rosetta-gami (DE3)pLysS cells carrying pREST-tPAP.

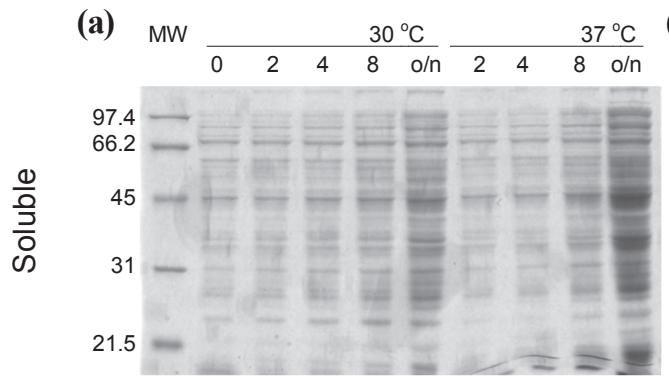

(b)

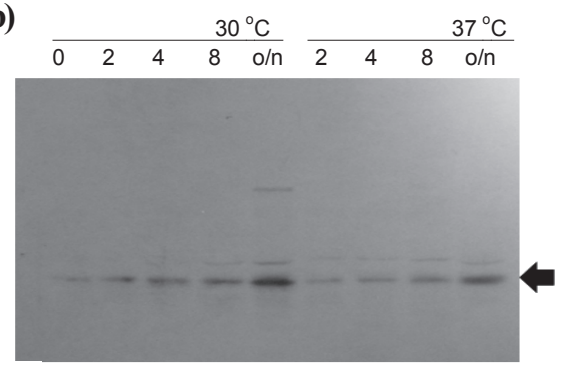

(c)

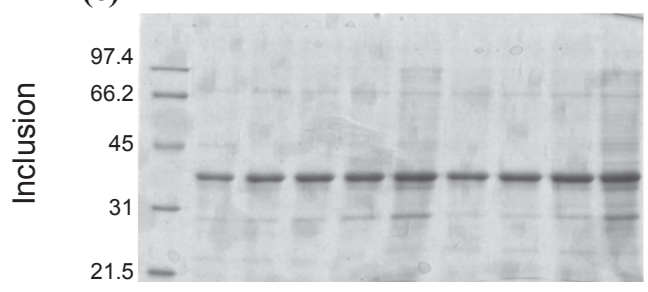

(d)

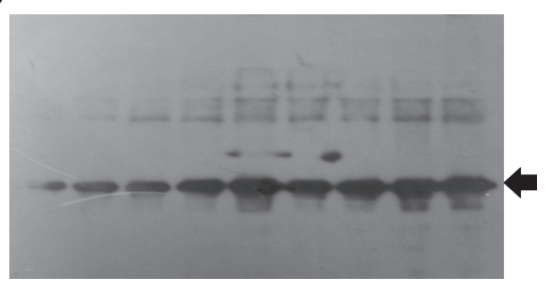

Figure 2. Expression of tPA P-domain in E. coli Rosetta-gami(DE3)pLysS cells at different temperatures. After induction of tPA P-domain expression with $0.1 \mathrm{mM}$ IPTG, cells were further incubated at either 30 , or $37{ }^{\circ} \mathrm{C}$ for various time. The supernatant (soluble) and pellet (inclusion) fractions of the whole cell lysate were subjected to electrophoresis on a $10 \%$ SDS-polyacrylamide gel and visualized by staining with Coomassie Brilliant Blue (a \& c), and by western blot analysis using anti-His-probe antibody (b \& d). Lane MW, molecular weight markers (Bio-Rad, low range). The numbers on the top of the gel show the time (in h; or o/n, overnight) after IPTG addition. 
refolded to acquire proteolytic activity.

It was presumed that a soluble form of tPA P-domain would be folded in its native state and exhibit biological activity. Although there was insignificant expression of soluble tPA Pdomain in most of the strains tested, the production of a soluble form was noticeably increased in Rosetta-gami(DE3)pLysS cells (Figure 1, bottom). For many proteins, such as human globin and cyclodextrin glycosyltransferase, the expression of soluble, exogenous proteins is enhanced at low temperatures. ${ }^{19,20}$ Similarly, the yield of soluble tPA P-domain was higher at $30{ }^{\circ} \mathrm{C}$ than at $37^{\circ} \mathrm{C}$ (Figure 2). In addition, more soluble protein was obtained after prolonged incubation (overnight). The formation of correctly folded protein, as evaluated by protease activity assays, was correlated with the amount of tPA $\mathrm{P}$-domain in the soluble extract fraction. Supernatant fractions from cultures induced for $2,4,8$, and $20 \mathrm{~h}$ at $30{ }^{\circ} \mathrm{C}$ had proteolytic activities of $829,1147,1642$, and $3219 \mathrm{IU} / \mathrm{mL}$, respectively, whereas induction for $2,4,8$, and $20 \mathrm{~h}$ at $37{ }^{\circ} \mathrm{C}$ produced activities of $717,860,1115$, and $2215 \mathrm{IU} / \mathrm{mL}$, respectively.

Purification of soluble tPA P-domain protein. Given that soluble cellular fractions were more likely to contain the active conformer, tPA P-domain protein was purified from the soluble fraction. The N-terminal (His) ${ }_{6}$-tag coding sequence present in the expression vector, pRSET-tPAP, enabled purification of polyhistidine-tagged tPA P-domain using immobilized metal ion affinity chromatography. This purification scheme avoids the cumbersome refolding steps described above, which result in extremely low yields, particularly with proteins containing several disulfide bonds.

The purification of tPA P-domain protein was performed as follows. A 1-L culture of Rosetta-gami(DE3)pLysS cells harboring pRSET-tPAP were induced at $30{ }^{\circ} \mathrm{C}$ for $4 \mathrm{~h}$ after the addition of $0.1 \mathrm{mM}$ IPTG. The supernatant from a high-speed centrifugation of cell lysate was loaded onto a $\mathrm{Ni}^{2+}$-NTA agarose column pre-equilibrated with $20 \mathrm{mM}$ Tris-Cl, $5 \mathrm{mM}$ imidazole, and $0.5 \mathrm{M} \mathrm{NaCl}, \mathrm{pH} 7.4$, and the protein was eluted using an imidazole gradient. The final purified tPA P-domain preparation yielded only one protein band, at $\sim 34 \mathrm{kDa}$, after SDSpolyacrylamide gel electrophoresis and Coomassie Brilliant Blue staining (Figure 3a). Routinely, about $1.2 \mathrm{mg}$ of soluble tPA P-domain were obtained from a 1-L culture.

Disulfide bonds formed in the purified tPA P-domain protein. The tPA P-domain should form six disulfide bonds, consisting of 12 cysteine residues. Disulfide bond formation was monitored by gel electrophoresis and Ellman's reagent. ${ }^{21}$ The P-domain protein was first electrophoresed in a SDS-polyacrylamide gel in the presence and absence of dithiothreitol (DTT), a reducing reagent. DTT was added in the sample loading buffer to a concentration of $100 \mathrm{mM}$, thereby rendering the proteins completely linearized. The presence of any disulfide bonds would cause the protein to migrate faster through the polyacrylamide gel, relative to the migration rate of the linearized (fully reduced) protein. ${ }^{22}$ The purified P-domain protein migrated more slowly in the presence of DTT (Figure 3a), indicating disulfide bond disruption by DTT. The migration rates of other proteins without disulfide bonds were not altered by the presence of reducing agent (data not shown). (a)

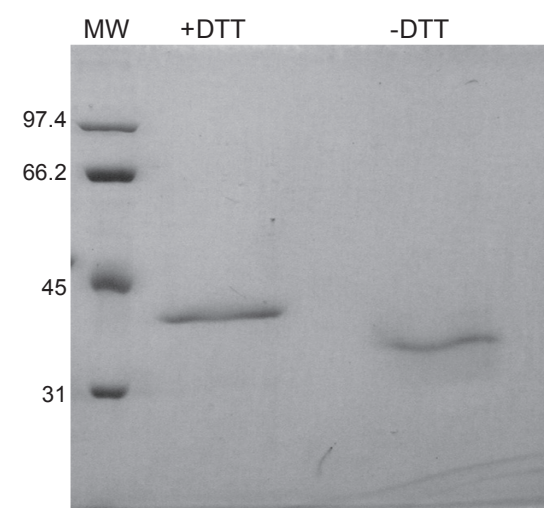

(b)

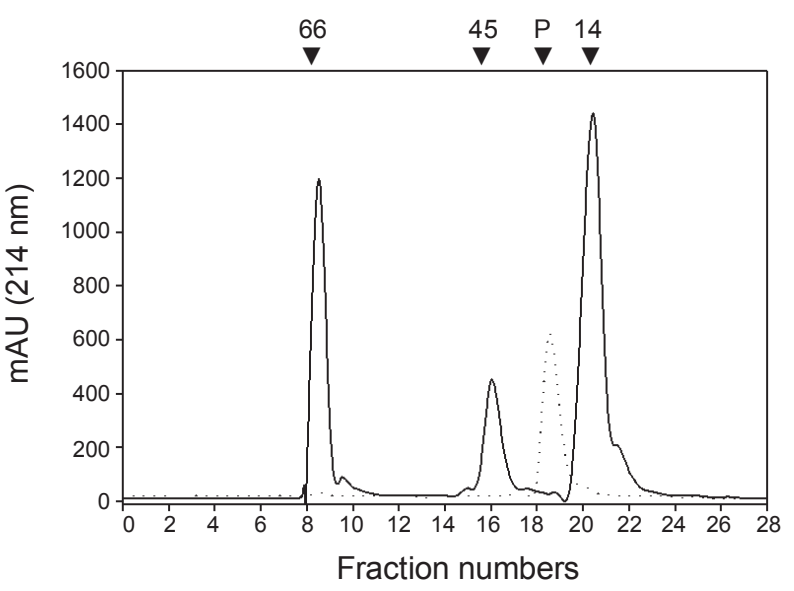

Figure 3. Structural integrity of the purified tPA P-domain protein. (a) SDS-polyacrylamide gel analysis of the purified tPAP-domain protein illustrating disulfide-bond formation. The purified soluble tPA P-domain proteins were subjected to electrophoresis on $10 \%$ SDS-polyacrylamide gels in the presence and absence of 0.1 M DTT. Protein bands were visualized with Coomassie Brilliant Blue staining. Lane MW, molecular weight markers (Bio-Rad, low range). Please note the faster migration of the tPA P-protein under non-reducing condition. (b) Gel filtration of tPA P-domain protein on a Superdex 75 column. tPA Pdomain protein $(1 \mathrm{mg} / \mathrm{mL})$ was applied onto a FPLC Superdex 75 column pre-equilibrated with $20 \mathrm{mM}$ Tris-HCl buffer, $\mathrm{pH} 7.4$ (broken line). Molecular size standards were bovine serum albumin $(66 \mathrm{kDa})$, recombinant human $\alpha_{1}$-antitrypsin $(44 \mathrm{kDa})$, and lysozyme $(14 \mathrm{kDa})$ in the same buffer (straight line). The flow rate was $1 \mathrm{~mL} / \mathrm{min}$, and protein-elution was monitored by UV absorbance at $214 \mathrm{~nm}$.

The number of remaining free thiols was quantified using Ellman's reagent. The number of free thiols per tPA P-protein was only 0.19 ; suggesting that 11.81 cysteines, if not all, out of the total 12 cysteines in PAP-protein, were involved in disulfide bonding.

Gel filtration of tPA P-protein on a Superdex-75 column resulted in an elution profile consistent with that of a $34-\mathrm{kDa}$ protein (Figure $3 \mathrm{~b}$ ), indicating that IPA P-protein exists mostly as a monomer under native conditions, instead of intermolecular disulfide-bonded oligomeric forms.

Activity of the purified tPA P-domain. The proteolytic activity of the purified, soluble P-domain protein was kinetically monitored using Spectrozyme tPA, a chromogenic substrate (Figure $4 \mathrm{a}$ ). The specific activity of the P-domain protein was $489,000 \mathrm{IU} / \mathrm{mg}$ protein, and was comparable to $522,000 \mathrm{IU} / \mathrm{mg}$ protein of full-length tPA. 
(a)

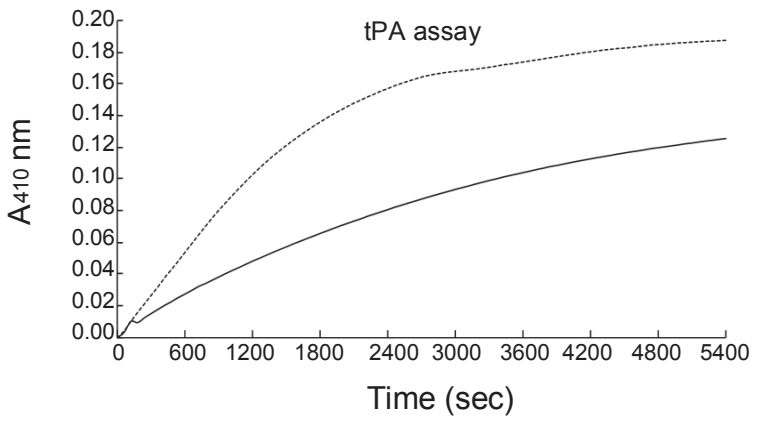

(b)

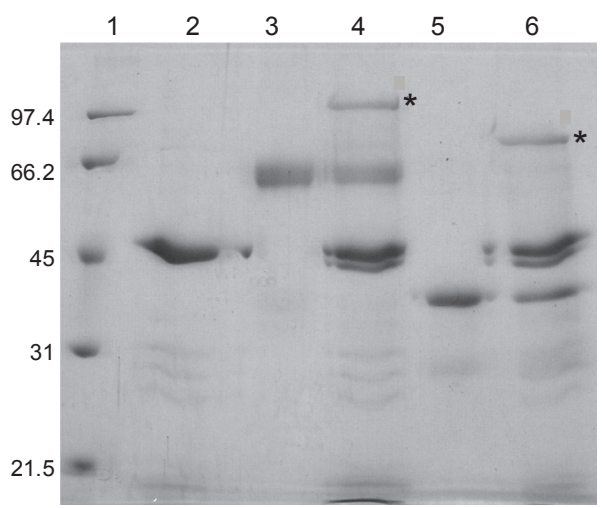

Figure 4. Activity of the purified tPA P domain protein. (a) Proteolytic activity of the purified tPA P protein. The proteolytic activity $0.5 \mu \mathrm{g}$ of purified tPA P-protein (straight line) or $1 \mu \mathrm{g}$ of full length tPA (broken line) was measured using $50 \mu \mathrm{M}$ Spectrozyme tPA as a substrate. Generation of the chromogenic product $p$-nitroaniline was monitored at $410 \mathrm{~nm}$ using a UV/visible spectrophotometer. (b) Covalently bound complex formation with PAI-1. Lane 1, molecular weight markers (Bio-Rad, low range); lane 2, $4 \mu \mathrm{g}$ of PAI-1 only; lane 3, $2 \mu \mathrm{g}$ of full length tPA only; lane 4, full length tPA incubated with PAI-1; lane 5, $1.5 \mu \mathrm{g}$ of purified tPA P-domain protein only; and lane 6 , purified tPA P-domain protein incubated with PAI-1. Asterisks indicate the migration positions of protease/PAI-1 complex.

Plasminogen activator inhibitor (PAI)-1 acts as a native inhibitor of fibrinolysis by inhibiting tPA and urokinase-type plasminogen activators in vivo. ${ }^{23}$ The ability to form an inhibitory complex with PAI-1 would therefore indicate proper folding of the tPA P-domain. This was assessed by monitoring the formation of a covalent protease-inhibitor complex with the P-domain protein. Full-length tPA binds to PAI-1 to form a 102-kDa complex. The P-domain protein also bound PAI-1, forming a $78-\mathrm{kDa}$ complex (Figure 4b). Thus, the above purification scheme for P-domain protein from the soluble fraction of the cell lysate yielded a pure, functional, recombinant protein with high specific activity.

Expression of active, soluble tPA P-domain in $\boldsymbol{E}$. coli. In the present report, E. coli strains and culture conditions were screened for efficient expression of tPA P-domain in a functional, soluble form. The expression and purification of human tPA from eukaryotic and prokaryotic sources has been described in several reports. ${ }^{4,24,25}$ However, tPA produced from animal cells is expensive and is rapidly cleared from the blood. ${ }^{5}$ Therefore, more industrially applicable recombinant hosts were sought for tPA production. Most previous studies on TPA expression and purification in E. coli were based on the recovery of tPA from inclusion bodies. ${ }^{26,27,28}$ Since tPA molecules should be highly disulfide-bonded, refolding steps were very complicated, including high concentration of arginine and mixed disulfide-solution of GSSH/GSH, etc. The refolded protein solution contained mostly misfolded proteins including protein aggregates and disulfide mismatched proteins. Therefore, the correctly folded monomeric proteins needed to be purified using several purification steps including expensive specific affinity resins, such as an Erythrina trypsin inhibitor-Sepharose, ${ }^{26}$ benzamidine-Sepharose ${ }^{27}$ and lysine-Sepharose. ${ }^{27,28}$ Worst of all, these schemes resulted in low-yields, despite of high costs and time consumed. Extracellular secretion of recombinant K2-P domain of tPA, using OmpA signal sequence, yielded a marginal amount of tPA at 7,000 IU/L culture even before purification. ${ }^{24}$ Our initial attempt to refold tPA P-domain protein from inclusion bodies was unsatisfactory due to aggregation, and efforts to optimize environmental factors, including salt concentration, detergent, and $\mathrm{pH}$, in order to minimize this aggregation were likewise unsuccessful. Although the amount of aggregated protein could be decreased, disulfide bonds were incompletely formed and possibly mismatched. Since recombinant proteins expressed in soluble forms are usually in their correctly folded forms, purification of the functional form can be simply achieved in one step using widely used affinity systems, such as $\mathrm{Ni}^{2+}$ - or glutathioneagarose columns. Therefore, expression of a soluble tPA was highly desirable. The results described here show that lowering the reducing power of the cytoplasm allowed the expression of soluble tPAP-domain. Supplementing the $E$. coli with tRNA genes for rarely used codons also promoted exogenous expression of tPA (Figure 1). Furthermore, the amount of tPA P-protein in the soluble component of the cell lysate was greater at a lower incubation temperature (Figure 2). The soluble monomeric tPA P-domain protein was purified by a single affinity step, and the purified protein retained its disulfide bonds (Figure 3a). The high proteolytic activity of the tPA P domain protein (Figure 4a) demonstrated that an active protease was obtained. tPA is physiologically regulated by PAI- 1 in vivo, by forming a covalent protease-inhibitor complex. The ability tPA $\mathrm{P}$ domain protein to form a covalently bound complex with its native inhibitor (Figure $4 \mathrm{~b}$ ) also suggested that a functional protease was obtained. Recombinant tPA has therapeutic potential for clinical conditions arising from improper blood clotting, which can lead to heart attack and stroke. The purification scheme for tPA P-protein described here is quite simple and more importantly enables the large-scale preparation of active protein. The expression of recombinant tPA domains in their active conformations will allow further characterization of their roles and regulation in several physiological processes. In addition, this method facilitates mutational analyses, which can be used to elucidate structure-function relationships. The current study also provides helpful information for tackling the difficulties in expressing functional eukaryotic proteins, such as the extracellular domains of receptors, in E. coli.

Acknowledgments. This work was supported by grants from the National Research Foundation of Korea (2010-0017215 \& 2010-0008293), and a grant number FPR09B1-091 of 21C 
Frontier Functional Proteomics Program from the Korea Ministry of Education, Science and Technology.

\section{References}

1. Rouf, S. A.; Moo-Young, M.; Chisti, Y. Biotechnol. Adv. 1996, 14, 239

2. Collen, D.; Lijnen, H. R. Arterioscler. Thromb. Vasc. Biol. 2009, 29, 1151.

3. Rijken, D. C.; Wijngaards, G.; Zaal-de Jong, M.; Welbergen, J. Biochim. Biophys. Acta 1979, 580, 140.

4. Collen, D.; Stassen, J. M.; Marafino, B. J.; Builder, S.; DeCock, F.; Ogez, J.; Tajiri, D.; Pennica, D.; Bennett, W. F.; Salwa, J. J. Pharmacol. Exp. Ther. 1984, 231, 146.

5. Lijnen, H. R.; Collen, D. Thromb. Haemost. 1991, 66, 88.

6. Allen, S.; Naim, H. Y.; Bulleid, N. J. J. Biol. Chem. 1995, 270, 4797.

7. Locker, J. K.; Griffiths, G. J. Cell Biol. 1999, 14, 267.

8. Jonda, S.; Huber-Wunderlich, N.; Glockshuber, R.; Mossner, E. EMBO J. 1999, 18, 3271

9. Bessette, P. H.; Aslund, F.; Beckwith, J.; Geortiou, G. Proc. Natl. Acad. Sci. USA 1999, 96, 13703.

10. Robinson, M.; Lilley, R.; Little, S.; Emtage, J. S.; Yarranton, G.; Stephens, P.; Millican, A.; Eaton, M.; Humphreys, G. Nucleic Acids Res. 1984, 12, 6663.

11. Ikemura, T. J. Mol. Biol. 1981, 146, 1.

12. Bringmann, U.; Mattes, R. E.; Buckel, P. Gene 1989, 85, 109.
13. Pennica, D.; Holmes, W. E.; Kohr, W. J.; Harkins, R. N.; Vehar, G. A.; Ward, C. A.; Bennett, W. F.; Yelverton, E.; Seeburg, P. H.; Heyneker, H. L.; Goeddel, D. V.; Collen, D. Nature 1983, 301, 214.

14. Wallén, P.; Pohl, G.; Bergsdorf, N.; Rånby, M.; Ny, T.; Jörnvall, H. Eur. J. Biochem. 1983, 1132, 681.

15. Zhang, Y.; Kanaho, Y.; Frohman, M. A.; Tsirka, S. E. J. Neurosci. 2005, 25, 1797.

16. Kim, Y. H.; Park, J. H.; Hong, S. H.; Koh, J. Y. Science 1999, 284, 647.

17. Rogove, A. D.; Siao, C.; Keyt, B.; Strickland, S.; Tsirka, S. E. J. Cell. Sci. 1999, 112, 4007.

18. Lee, H.-Y.; Hwang, I.-Y.; Im, H.; Koh, J.-Y.; Kim, Y.-H. J. Neurochem. 2007, 101, 1236.

19. Lim, P. S.; Kwon, M. J.; Kim, S. K.; Nam, S. W. J. Microbiol. Biotech. 2004, 14, 216.

20. Weickert, M. J.; Pagratis, M.; Curry, S. R.; Blackmore, R. Appl. Environ. Microbiol. 1997, 63, 4313.

21. Ellman, G. L. Arch. Biochem. Biophys. 1959, 82, 70.

22. Baek, J. H.; Im, H.; Kang, U. B.; Seong, K. M.; Lee, C.; Kim, J.; Yu, M. H. Protein Sci. 2007, 16, 1842.

23. Vaughan, D. E. J. Invest. Med. 1998, 46, 370.

24. Manosroi, J.; Tayapiwatana, C.; Götz, F.; Werner, R. G.; Manosroi, A. Appl. Environ. Microbiol. 2001, 67, 2657.

25. Mattes, R. Semin. Thromb. Hemost. 2001, $27,325$.

26. Vindigni, A.; Cera, E. D. Protein Sci. 1998, 7, 1728.

27. Hua, Z.-C. Biochem. Mol. Biol. Intl. 1997, 41, 815.

28. Wilhelm, O. G.; Jaskunas, S. R.; Vlahos, C. J.; Bang, N. U. J. Biol. Chem. 1990, 265, 14606. 